\title{
A Two-Month-Old Child with Vascular Ectasia: A Case Report Diagnosed by Molecular Karyotyping
}

\author{
Ozlem Tolu Kendir ${ }^{1}$ Hayri Levent Yilmaz ${ }^{1}$ Sevcan Bozdogann ${ }^{2,3}$ Atıl Bisgin ${ }^{2,3}$ Tugçe Celik ${ }^{1}$ \\ Ozgur Surmelioglu ${ }^{4}$ Figen Doran ${ }^{5}$
}

${ }^{1}$ Department of Pediatrics, Çukurova Üniversity, Balcali Hospital, Adana, Turkey

2 AGENTEM (Adana Genetic Diseases Diagnosis and Treatment

Center), Cukurova University, Adana, Turkey

${ }^{3}$ Medical Genetics Department of Balcali Clinics and Hospital, Cukurova University Faculty of Medicine, Adana, Turkey

${ }^{4}$ Department of Otorhinolaryngology, Çukurova Üniversity, Balcali

Hospital, Adana, Turkey

${ }^{5}$ Department of Pathology, Çukurova Üniversity, Balcali Hospital, Adana, Turkey

Address for correspondence Ozlem Tolu Kendir, MD, Department of Pediatrics, Çukurova Üniversity, Balcali Hospital, Adana, Turkey (e-mail: otolu80@yahoo.com).

J Pediatr Genet 2019;8:20-23.
Abstract
Keywords
- angiodysplasia
- vascular ectasia
- duplication of chromosome 2
- molecular karyotyping

Gastrointestinal angiodysplasia can be encountered in cases with aortic stenosis, inflammatory gastrointestinal conditions, von Willebrand disease or vascular damage, and degenerative changes. Predisposing factors have been described in four adults with vascular ectasia located in the stomach, duodenum, and the distal esophagus. Here, we report a 2-month-old infant with vascular ectasia in the proximal esophagus and diagnosed by molecular karyotyping. This is the first case of vascular ectasia in the proximal esophagus in a pediatric patient.

\section{Introduction}

Vascular ectasia has been previously reported in four adult patients who had predisposing factors; however, literature review did not find such condition in pediatric patients. Here, we demonstrate the first report of vascular ectasia in the proximal esophagus in a pediatric patient.

\section{Case Report}

A 2-month-old female infant presented with crying and restlessness to our pediatric emergency unit. This baby girl was delivered at 38 weeks gestational via cesarean section with birth weight of $3,160 \mathrm{~g}$. She was admitted to the neonatal intensive care unit (NICU) because of respiratory distress. She was identified to have an atrial septal defect, a ventricular septal defect, and patent ductus arteriosus by echocardiography when she was in NICU.

received

April 19, 2018

accepted after revision

July 18,2018

published online

August 22, 2018

Upon the admission of 2-month of age, she was restless, but still revealed an interest for her surroundings. The body temperature was $36^{\circ} \mathrm{C}$, the heart rate was 160 beats $/ \mathrm{min}$, the respiratory rate was 32 breaths/min, and the blood pressure was $80 / 50 \mathrm{~mm} / \mathrm{Hg}$. On inspection, she had dysmorphic features; therefore, genetic testing and counseling were initiated. On auscultation, there was a grade 3/6 systolic murmur. Examinations of the other organ systems showed normal results.

The patient did not have respiratory distress as shown in her neonatal period, and stridor was observed during inspiration. Pulmonary X-ray was normal, and she did not have signs of an active infection. She was suspected of having laryngomalacia, anomalies of the upper respiratory tract, or foreign body. The otorhinolaryngology check-up by using endoscopy revealed a mass located in the postsinusoidal region and in the entrance of the esophagus extending to the laryngeal lumen. It was considered to be a hemangioma. The

Copyright (c) 2019 by Georg Thieme Verlag KG, Stuttgart · New York
DOI https://doi.org/ $10.1055 / \mathrm{s}-0038-1669385$. ISSN 2146-4596. 
patient was then admitted to the pediatric inpatient unit for further investigations. Magnetic resonance imaging of the neck showed normal results. No gastrointestinal bleeding was found and the stridor on deep inspiration remained.

The edematous mass was located in the postcricoid, interarytenoid region and involved the anterior wall of the esophagus. It was excised with $\mathrm{CO}_{2}$ laser under laryngoscopy, bronchoscopy, and esophagoscopy. The pathological examination of the mass revealed a diagnosis of vascular ectasia, with dilated, tortuous mucosal capillaries and fibrin thrombi, surrounded by fibrohyalinosis with fibromuscular hyperplasia of lamina propria (-Fig. 1). The lesion showed mild chronic inflammation in the superficial lamina propria. Postsurgical follow-up did not reveal any additional issues. No other medical treatment has been introduced.

The clinical genetic evaluation showed that this baby girl had long face, microphthalmia, epicanthal folds, strabismus, cup shaped ears, broad and short philtrum, bilateral clinodactyly, and hockey line. She had mildly motor development delay, although her measurements were normal (head circumference and weight: $25-50$ th centile; length: 50-75th centile). The karyotype analysis was normal $(46, \mathrm{XX})$; however, chromosomal microarray analysis using the Affymetrix CytoScan Optima platform identified a $11.5 \mathrm{Mb}$ distal deletion of $4 \mathrm{q} 34.3-\mathrm{q} 35.2$ and a $13.5 \mathrm{Mb}$ distal duplication at 2p24.3-25.3 ( - Table 1). Parental studies including the cytogenetic analysis and molecular karyotyping revealed normal results.

\section{Discussion}

Angiodysplasia presents with massive or repeated bleedings and anemia. If the lesion is seen endoscopically, it is bright red, flat, and well-defined or looks like Dryopteris filix-mas. ${ }^{1}$ Angiodysplasia usually appears in the stomach and duodenum and is rarely seen in the esophagus. ${ }^{2}$ It may appear in the presence of aortic stenosis, inflammatory gastrointestinal conditions, and von Willebrand disease. Mechanical factors, such as vascular damage due to bleeding into the submucosal system caused by vigorous peristalsis or increased intraluminal pressure, may play a role in some cases. $^{1,3}$ In addition, it may result from progressive enlargement of the normal vascular structures due to vascular degenerative changes in advanced age. Most cases of angiodysplasia have mucosal and submucosal lesions that are not seen on macroscopic examination. ${ }^{1}$

Okano et $\mathrm{al}^{3}$ reported that a 26-year-old male with Fabry's disease and vascular ectasia in his esophagus. Khanna et $\mathrm{al}^{4}$ also presented a case of esophageal vascular ectasia. A 76-year-old man with a history of gastric antral vascular
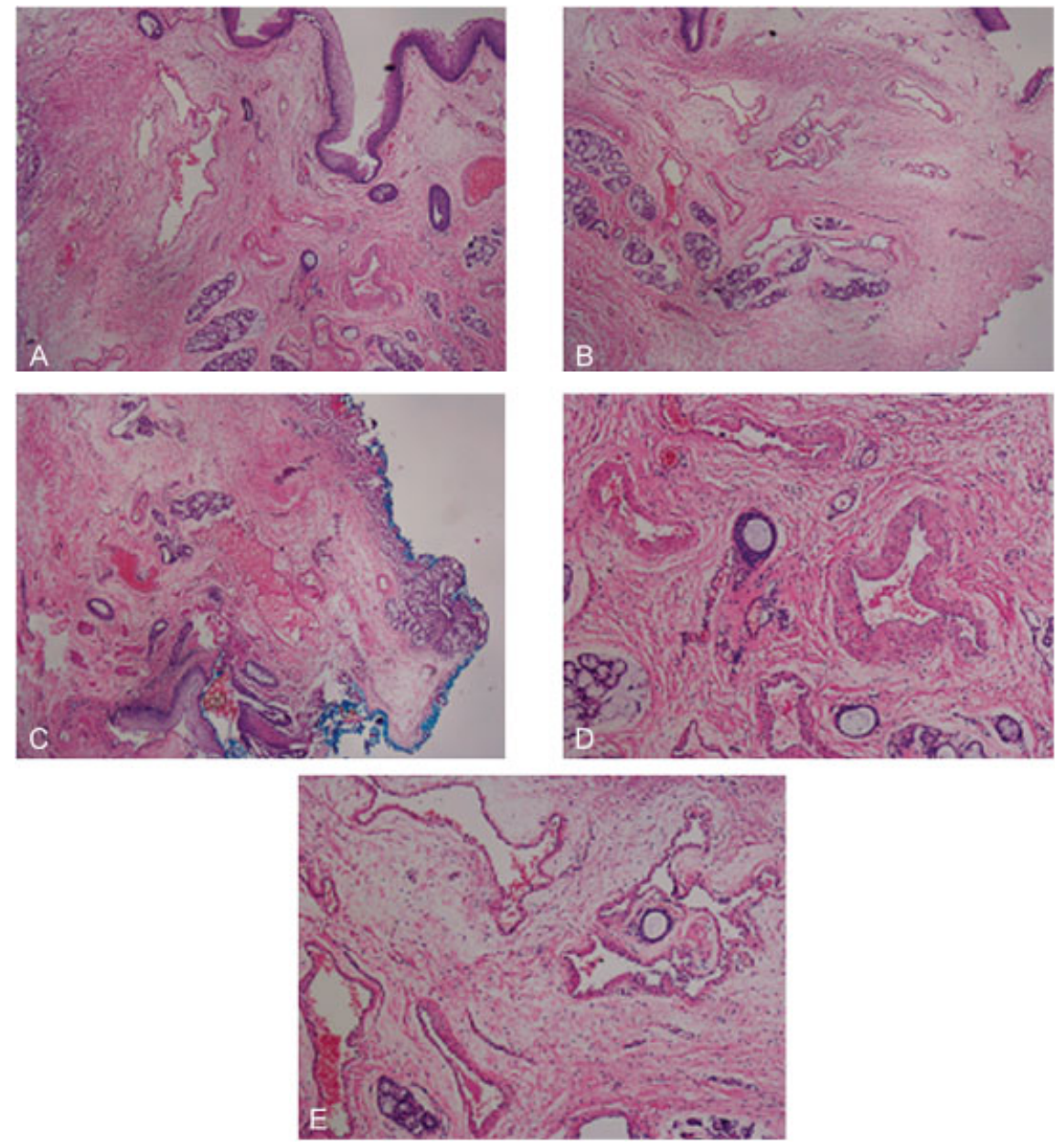

Fig. 1 Views of the excised tissue obtained on pathological examinations. 
Table 1 The list of the genes involved (according to Human Genome Build 37)

\begin{tabular}{|l|l|}
\hline $\begin{array}{l}\text { Duplicated genes } \\
\text { 2p24.3-25.3 (chr2:72.184-13.486.778) }\end{array}$ & $\begin{array}{l}\text { Deleted genes } \\
\text { 4q34.3-q35.2 (chr4:179.005.829-190.880.409 }\end{array}$ \\
\hline SH3YL1, ACP1, FAM150B, TMEM18, C2orf90, SNTG2, TPO, PXDN, & MGC45800, MIR1305, ODZ3, DCTD, FAM92A3, C4orf38, \\
MYT1L, LOC730811, TSSC1, TTC15, ADI1, RNASEH1, RPS7, & WWC2, CLDN22, CDKN2AIP, ING2, RWDD4A, C4Orf41, \\
COLEC11, ALLC, SOX11, DKFZ7761K2322, LOC400940, CMPK2, & STOX2, ENPP6, IRF2, CASP3, CCDC111, MLF11IPACSL1, \\
RSAD2, RNF144A, LOC339788, ID2, KIDINS220, MBOAT2, ASAP2, & UNQ9368, HELT, SLC25A4, KIA1430, SNX25, LRP2BP, \\
ITGB1BP1, CPSF3, IAH1, ADAM17, YWHAQ, TAF1B, GRHL1, KLF11, & ANKRD37, UFSP2, C4Orf47, CCDC110, PDLIM3, SORBS2, \\
CYS1, RRM2, C2Orf48, HPCAL1, ODC1, SNORA80B, NOL10, & TLR3, FAM149A, CYP4V2, KLKB1, F11, MTRN1A, FAT1, \\
ATP6V1C2, PDIA6, KCNF1, C2OIf50, PQLC3, ROCK2, E2F6, & ZFP42, TRIML2, TRIML1, FRG1 \\
GREB1, NTSR2, LPIN1, TRIB2 & \\
\hline
\end{tabular}

ectasia undergoing aortal valve replacement and receiving anticoagulant therapy had esophageal vascular ectasia extending from the gastroesophageal region to Barrett's esophagus. Patients with gastric antral vascular ectasia were frequently shown to have vascular ectasia in the gastric cardia. ${ }^{5,6}$ Liu et al $^{7}$ also reported a 68-year-old woman suspected to have a hepatic, renal, or autoimmune disease, and a 61-year-old woman having recurrent melena both with vascular ectasia in the gastric antral region.

Most of the cases in literature with gastric antral vascular ectasia related to the portal hypertension and hepatic cirrhosis. Clinical heterogeneity makes it difficult to differentiate the gastric antral vascular ectasia that occurred due to neurohumoral factors from portal hypertensive gastropathy, which is more related to vascular congestion and edema, though the pathophysiology and treatment strategies are different. ${ }^{8,9}$ Portal hypertensive gastropathy is mostly treated with medical treatment agents; in contrast, laser is mostly used in the treatment of gastric antral vascular ectasia. ${ }^{10}$ When a patient had avascular ectasia which is located at the proximal of esophagus, there was no other chronic diseases. The vascular ectasia in this patient had extended from the proximal of esophagus to the larynx with the finding of upper airway obstruction, which could be caused by infections, structural anomalies such as laryngomalacia, congenital vocal cord paralysis, subglottic stenosis, hemangioma, or cystic hygroma. ${ }^{11,12}$

There have been four adult cases of vascular ectasia in esophagus reported in the literature. The case presented here is the first pediatric case of vascular ectasia accompanied with submicroscopic chromosomal anomalies. In the previously reported cases, the vascular ectasias have been located in the distal and middle esophagus and the gastric antral regions. The vascular ectasia in our case is located in the proximal esophagus. In addition, the previous cases have been reported to have various acquired and mechanical predisposing factors, whereas the present case does not have any predisposing factors. Therefore, vascular ectasia could be attributed to unbalanced chromosomal rearrangements and part of a developmental anomaly.

The reported patient here showed that the distal deletion at 4q34.3-35.2 and distal duplication at 2p24.3-25.3 was de novo. A patient with a deletion of $12.7 \mathrm{Mb}$ of $4 \mathrm{q} 34.1 \mathrm{q} 35.2$ had congenital heart defects, Pierre Robin sequence, intellec- tual disability, and dysmorphic features. ${ }^{13}$ In addition, another patient with deletion at 4q34-q35 region had a phenotype resembling 22q11.2 deletion syndrome. ${ }^{14}$ Our case also had 13.5 Mb duplication of 2p24.3-25.3. There are only a few cases in literature with duplication of chromosome 2 but not with the same breakpoints and these duplications were inherited due to parental structural chromosomal abnormalities. ${ }^{15-19}$

To our knowledge, this is the first pediatric vascular ectasia case with a concurrent de novo distal duplication of $2 \mathrm{p}$ and distal deletion of $4 \mathrm{q}$.

\section{Compliance with Ethical Standards}

Ethical Statement This article does not contain any studies with human or animal subjects performed by any of the authors.

\section{Conflict of Interest}

None declared.

\section{Note}

Authors have permission from the patient's parents.

\section{References}

1 Pathology G. Cecilia M. Fenoglio Ch 4; LWW.Com. 2009:219-220

2 Foutch PG. Angiodysplasia of the gastrointestinal tract. Am J Gastroenterol 1993;88(06):807-818

3 Okano H, Shiraki K, Tsuneoka K, et al. Esophageal vascular ectasia associated with Fabry's disease. Gastrointest Endosc 2001;53 (01):125-126

4 Khanna S, Arora AS, Topazian MD. Esophageal vascular ectasia. Endoscopy 2011;43(Suppl 2 UCTN):E281

5 Rosenfeld G, Enns R. Argon photocoagulation in the treatment of gastric antral vascular ectasia and radiation proctitis. Can J Gastroenterol 2009;23(12):801-804

6 Feitoza AB, Gostout CJ, Burgart LJ, Burkert A, Herman LJ, Rajan E. Hydroxypropyl methylcellulose: a better submucosal fluid cushion for endoscopic mucosal resection. Gastrointest Endosc 2003; 57(01):41-47

7 Liu F, Ji F, Jin X, et al. Gastric antral vascular ectasia in two noncirrhotic patients involved large area stomach: case report and literature review. J Interv Gastroenterol 2013;3(03):107-110

8 Wang J, Stine JG, Cornella SL, Argo CK, Cohn SM. Patients with gastric antral vascular ectasia (GAVE) are at a higher risk of gastrointestinal bleeding in the absence of cirrhosis. J Clin Transl Hepatol 2015;3(04):254-259

9 Garg H, Gupta S, Anand AC, Broor SL. Portal hypertensive gastropathy and gastric antral vascular ectasia. Indian J Gastroenterol 2015;34(05):351-358 
10 Cordeiro de Azevedo Conejo F, Fracassi MTM, Assef MS, Ribeiro MA, Szutan LA, Ferreira FG. Elevated gastric antrum erosions in portal hypertension patients: peptic disease or mucosal congestion? Korean J Gastroenterol 2017;69(05):278-282

11 Gupta N, Goyal A, Singh PP, Sharma S. Isolated laryngeal lymphangioma: a rarity. Indian J Otolaryngol Head Neck Surg 2011;63 (01, Suppl 1):90-92

12 Moriones Robayo CA, Guerra Ortiz CP. Histoplasmosis laryngeal: report first case in Colombia. Colomb Med (Cali) 2014;45(04): 186-189

13 Rossi MR, DiMaio MS, Xiang B, et al. Clinical and genomic characterization of distal duplications and deletions of chromosome 4q: study of two cases and review of the literature. Am J Med Genet A 2009;149A(12):2788-2794

14 Cuturilo G, Menten B, Krstic A, et al. 4q34.1-q35.2 deletion in a boy with phenotype resembling 22q11.2 deletion syndrome. Eur J Pediatr 2011;170(11):1465-1470

15 Atik T, Durmaz B, Yorganci OU, Cogulu O, Kioutsouk M, Ozkinay F. Partial trisomy 2p24-> pter and monosomy 18q22.1- qter result- ing from parental translocation. Genet Couns 2013;24(02): 179-184

16 Manolakos E, Vetro A, Papadopoulou E, et al. Partial trisomy 2p and partial monosomy $2 q$ arising from a paternal intrachromosomal $2 q-i n t o-2 p$ between-arm insertion and paracentric inversion: molecular cytogenetic characterization of a four-break rearrangement. Cytogenet Genome Res 2013;140(01):12-20

17 Martínez-Juárez A, Uribe-Figueroa L, Quintana-Palma M, RazoAguilera G, Sevilla-Montoya R. Pure trisomy 2p syndrome in two siblings with an unbalanced translocation and minimal terminal 12 q monosomy characterized by high-density microarray. Cytogenet Genome Res 2014;142(04):249-254

18 Tirado CA, Henderson S, Uddin N, et al. Cytogenetic and molecular characterization of a partial trisomy $2 \mathrm{p}$ arising from inverted duplication of $2 p$ with terminal deletion of 2 pter. Am J Med Genet A 2009;149A(11):2507-2512

19 Roggenbuck JA, Fink JM, Mendelsohn NJ. Unique case of trisomy 2p24.3-pter with no associated monosomy. Am J Med Genet $2001 ; 101(01): 50-54$ 